De Ruyter, A. \& Nielsen, B. (2018). Brexit: one year on from Article 50 - Reflections from Academia, Business and Politics

\title{
Explaining the Brexit Vote: A socio-economic and psychological exploration of the referendum vote
}

David Hearne, Dr Rebecca Semmens-Wheeler and Dr Kimberley M Hill

\section{Introduction}

Since the referendum on membership of the European Union (EU) in June 2016, research continues to emerge on the socio-economic and psychological factors affecting Britain's decision. There is a growing social science literature investigating voting patterns in the 2016 referendum. Although the vote to leave the EU appeared to mark a seismic shift in the British polity, in reality the forces that drove it were visible beforehand. The single most powerful predictor of the share of the Leave vote in an area is the support for UKIP in European Parliament elections 2 years previously (M. J. Goodwin \& Heath, 2016).

Nevertheless, whilst a number of socio-political hypotheses have been proposed to explain the result, they are typically not grounded in psychological theory. This is curious, as our desire is surely to understand why the vote unfolded as it did. Many of these processes are fundamentally social, embedded within communities and collective decision making. Therefore, most of the theories we mention in this chapter are explicitly Social Psychological. For example, whilst identity is individual, we only understand ourselves by our interactions with others and hence identity is deeply social. This cross-disciplinary chapter aims to contribute to widening the academic debate around UK's decision to leave the EU by providing a bridge between social science research and that on the psychological processes behind Brexit. We posit this as a first pass at the problem rather than delivering any final answers, considering a range of psychological factors, including theories related to social identity, integrated threat, aversion amplification, locus of control and personality, and how these might relate to economic and demographic variables. 
De Ruyter, A. \& Nielsen, B. (2018). Brexit: one year on from Article 50 - Reflections from Academia, Business and Politics

\section{A Simple Econometric Model of the Brexit Vote}

Individual-level polling data suggests several demographic factors have significant associations with the probability that a person voted for Brexit (Ashcroft, 2016). Education, social class, education and ethnicity all have predictive power (ibid.). All of these factors are highly correlated with one another and we want to disentangle the impact of each of them after controlling for the others. We therefore posit a simple statistical model of the Brexit vote at the LA level where we can run multivariate analysis of this nature. Like most other studies on the Brexit vote (e.g. Becker, Fetzer, \& Novy, 2017; M. J. Goodwin \& Heath, 2016) we make use of aggregate data regressing explanatory variables on the percentage of eligible votes cast that were in favour of leaving the EU using data from the Electoral Commission (2016).

Aggregate data in this case replace polling data, which are expensive to collect and subject to non-response bias, recall error, sampling difficulties and a number of other issues.

Ultimately, any analysis based on aggregate data cannot show the determinants of the vote at an individual level. Our results are thus suggestive rather than absolute and we cannot necessarily use them to infer causality ${ }^{1}$.In theory the fact that the dependent variable is a proportion poses a problem but in practice there are no predicted results outside the interval and Ordinary Least Squares (OLS) provides a linear model that should be locally appropriate ${ }^{2}$. More problematic are issues of model selection and errors-in-variables. Although we have up-to-date information on many variables, these are statistical samples subject to measurement error. Future work will undoubtedly want to consider using instrumental variables estimation in order to avoid bias.

Model selection is another key issue: there are a plethora of variables that might be included and an entirely atheoretical approach is unlikely to be justified. To be truly rigorous, inference (in the mould of classical statistics) should not be on data already seen, although in practice it is impossible to ignore the results of other researchers with the same data. Becker et al. (2017) use a best subset selection procedure to an OLS regression to

\footnotetext{
${ }^{1}$ Those in professional occupations were on average less likely than machine operatives to vote for Brexit, but this does not imply that a solicitor who decides to retrain as a machine operative (or vice versa) will suddenly switch their vote.

${ }^{2}$ When we ran a beta regression the results were qualitatively similar in terms of statistically significant variables.
} 
De Ruyter, A. \& Nielsen, B. (2018). Brexit: one year on from Article 50 - Reflections from Academia, Business and Politics

derive a statistically sound model, including a number of innovative variables not previously seen in the literature.

Data

Given the findings of Ashcroft (2016), we include demographic data on ethnicity, education, age and a proxy for social class. Competition for scarce resources, austerity, immigration and a lack of opportunities in declining regions and "places that don't matter" (RodríguezPose, 2018, p. 189) may have had an impact on the Brexit vote so we included variables capturing these.

Data on ethnicity was taken from the Annual Population Survey (ONS, 2017a) ${ }^{3}$. Whilst this contains data on several ethnic groups and the proportion born abroad, they have large coefficients of variation, which is likely to lead to inconsistent results (due to the errors-invariables problem). Worse, some LAs have no result at all. Therefore, we instead consider the change in the proportion of the population which is "white British" in each LA. These data are much more robust but do not allow us to consider European and non-European ethnic groups separately.

We consider the proportion of residents in each LA who were white British and the change in this proportion over ten years. The former functions as our measure of ethnicity whilst the latter is a measure of immigration intensity. Data on education are available from the same data source. In order to ensure comparability across the UK we consider education by NVQ equivalent, including variables on the proportion of the population with NVQ4+ (broadly speaking equivalent to a degree) and those with an NVQ2 (equivalent to $5 \mathrm{~A}^{*}-\mathrm{C}$ GCSEs) or below. The APS contains data on the proportion of the population in Standard Occupational Classification (SOC) categories 1-3, which includes managers, professionals, associates and technical staff ${ }^{4}$.

Age data come from the ONS's population estimates. We include the proportion of over 65s and the proportion of under 30 s in each LA. Also included are two measures of austerity originally posited by Becker et al. (2017), specifically the proportion of NHS cancer patients

\footnotetext{
${ }^{3}$ Henceforth APS

${ }^{4}$ Although there is no agreed measure of social class, this is widely seen as an acceptable proxy for those in socalled "middle class" jobs.
} 
De Ruyter, A. \& Nielsen, B. (2018). Brexit: one year on from Article 50 - Reflections from Academia, Business and Politics

treated within 62 days and the total reduction in benefit spending per working adult in each LA as reported by the Financial Times (2013).

Median income for residents of each LA is taken from the Annual Survey on Hours and Earnings (ONS, 2017b). We take an average of median pay by LA over the past three years in order to minimise the errors-in-variables problem. Given the evidence on the "left-behind", it seems possible that individuals living in areas that have experienced particular economic difficulties since European enlargement are more likely to have voted Leave if the "threat" posed by a weaker economy has led them to increased in-group identification. Although we have no direct evidence, we include a number of variables likely to be linked to economic strength and resilience. This includes the change in median pay over the past decade (we use a 3-year average and compare it to the same 3-year period a decade earlier) from ASHE and the unemployment rate by LA, which is sourced from the APS.

The share of the economy made up by the manufacturing sector in 1998 (ONS, 2017c) is also included as a proxy for economic decay. Given the precipitous decline in manufacturing employment over the past 20 years it's probable that areas with a larger manufacturing base have been hardest hit by deindustrialisation. Given some of the qualitative findings regarding "regret", which we discuss later, we also included the Leave vote share in 1975 as a variable alongside regional dummies.

\begin{tabular}{|c|c|c|}
\hline Results & & \\
\hline Coefficient & Estimate & \\
\hline (Intercept) & $\begin{array}{c}54.71 \\
(11.75)\end{array}$ & $* *$ \\
\hline$\%$ of Population who are white British & $\begin{array}{c}0.23 \\
(0.05)\end{array}$ & $* *$ \\
\hline $\begin{array}{l}\% \text { growth in full-time salaries over the } \\
\text { past decade }\end{array}$ & $\begin{array}{l}-0.03 \\
(0.04)\end{array}$ & \\
\hline Median full-time salaries (in $f 1000$ ) & $\begin{array}{c}0.04 \\
(0.13)\end{array}$ & \\
\hline $\begin{array}{l}\% \text { increase in the proportion of the } \\
\text { population who are not white British }\end{array}$ & & \\
\hline over the past decade & $\begin{array}{c}0.58 \\
(0.09)\end{array}$ & $* *$ \\
\hline$\%$ with NVQ4+ & $\begin{array}{l}-0.47 \\
(0.09)\end{array}$ & $* *$ \\
\hline$\%$ over 65 & $\begin{array}{c}0.14 \\
(0.10)\end{array}$ & \\
\hline
\end{tabular}


De Ruyter, A. \& Nielsen, B. (2018). Brexit: one year on from Article 50 - Reflections from Academia, Business and Politics

$\begin{array}{lcl}\text { \% under } 30 & -0.34 & * * \\ & (0.09) & \\ \text { \% who voted Leave in } 1975 & 0.19 & * * \\ & (0.07) & \\ \text { East Midlands dummy } & 1.28 \\ & (1.03) & \\ \text { London dummy } & 1.76 \\ & (1.83) & \\ \text { North East dummy } & 1.04 \\ & (1.89) & \\ \text { North West dummy } & -1.15 & \\ & (1.40) & \\ \text { Scotland dummy } & -14.54 & * * \\ & (1.61) & \\ \text { South East dummy } & 1.54 \\ & (0.99) & \\ \text { South West dummy } & -1.53 \\ & (1.16) & \\ \text { Wales dummy } & -3.68 \\ & (1.59) & \\ \text { West Midlands dummy } & 2.55\end{array}$

Residual standard error: 4.148 on 301 degrees of freedom (52 observations missing) $* *=$ significant at $1 \% \quad *=$ significant at $5 \%$ $R^{2}: 0.858, \quad$ Adjusted $R^{2}: 0.8467$

Heteroscedasticity-robust standard errors were used. After controlling for the other factors, LAs with a higher proportion of people in the "white British" ethnic group tended to vote 
De Ruyter, A. \& Nielsen, B. (2018). Brexit: one year on from Article 50 - Reflections from Academia, Business and Politics

Leave more heavily. Each additional percentage point was associated with a 0.23 percentage point increase in the Leave vote.

In contrast, the change in the proportion of white Britons over the past decade in an area is negatively associated with the Leave vote. Whilst this might initially seem counterintuitive, the first variable is a measure of the ethnic composition of an area whereas the second is a measure of the change in ethnic composition and is strongly associated with migration. Ceteris paribus, exposure to immigration significantly increases the Leave vote of an area: each 1 percentage point rise is associated with a 0.58 percentage point increase in the Leave vote.

The proportion of highly educated individuals (NVQ4+) is strongly negatively related to the Leave vote but lower education levels appear to have little effect. The difference between those with A-levels and those who left school at 16 is not significant. Although a high proportion of under-30s is associated with a stronger Remain vote, the proportion of over$65 \mathrm{~s}$ in an LA is not statistically significant after controlling for other factors (e.g. the lower education levels of this group). The latter chimes with the results of Liberini, Oswald, Proto, and Redoano (2017) who use a completely different dataset and methodology, giving confidence in the finding. More generally, these results fit nicely with the findings of Fielding (2018), who argues that find the inhabitants of areas with a high density of universities hold social views that are significantly more liberal than inhabitants of other areas.

In contrast to our hypotheses on regret and roadshow findings (De Ruyter, Hearne, Guy, Semmens-Wheeler, \& Goodwin, 2018, Forthcoming; Semmens-Wheeler \& Hill, In prep.), a higher vote in favour of leaving in 1975 is associated with a higher vote in favour of leaving in 2016, suggesting a degree of regional consistency over time. Nevertheless, this effect is quite weak and there is considerable heterogeneity. Given the large majority in favour of remaining in 1975 , it is clear that many individuals must have changed their minds in order to deliver the Brexit result of today.

Being in Scotland was associated with a near 15 percentage point drop in the Leave share. Intriguingly, after controlling for demographic factors regions in Wales also voted Leave less strongly than equivalent regions in England (by around 3.7 percentage points). The only English region that differed from the rest was the West Midlands (which voted Leave more 
De Ruyter, A. \& Nielsen, B. (2018). Brexit: one year on from Article 50 - Reflections from Academia, Business and Politics

strongly than might be expected from its demographics). The proportion of an LA's population in SOC groups 1-3 was associated with a lower Leave vote, suggesting that occupation was an important marker. Finally, the proportion of cancer patients treated within 62 days was significant at the $5 \%$ level, although the effect was quantitatively small. This is indicative that there could have been an austerity effect on the vote, although more evidence will be needed before more concrete judgements can be made. We cannot reject the null hypothesis that the coefficients on the remainder of the variables are zero (either individually or jointly), although they mostly have the expected signs. Inability to reject the null does not necessarily mean that these effects do not exist. If we use a best subset selection procedure minimising the Schwartz-Bayesian Information Criterion (BIC) then we arrive at the following model:

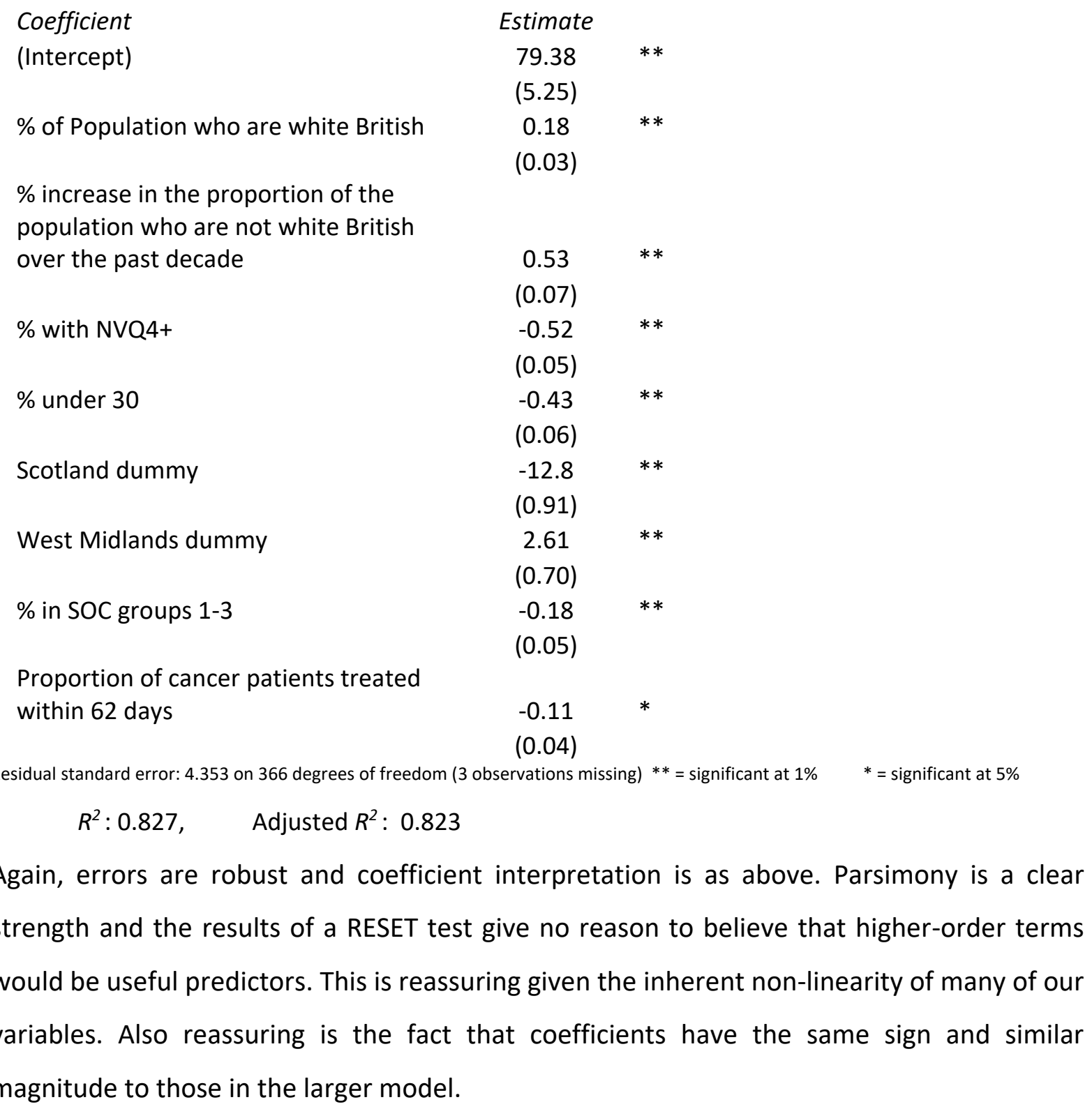


De Ruyter, A. \& Nielsen, B. (2018). Brexit: one year on from Article 50 - Reflections from Academia, Business and Politics

There remain a number of troubling econometric issues that future work will undoubtedly want to concentrate on in order to refine our understanding further. Future work will undoubtedly want to make heavier use of ward-level data and although all efforts have been made to minimise errors-in-variables, researchers may wish to consider using instruments to avoid this problem entirely. Similarly, given the non-linearity of the dependent variable researchers are likely to wish to experiment with non-linear regression, although this is unlikely to overturn any of the results found by ourselves and other researchers. Future work will also want to try and ascertain the individual level coefficients associated with several of these variables (e.g. how much does being a graduate reduce the probability that one voted for Brexit). Finally, further attention needs to be paid to how to measure labour market insecurity and precariousness, as well as perhaps using additional datasets to enhance our understanding.

\section{Factors underlying our results}

We now employ a social psychological approach to understand the quantitative results above. Having identified several variables that help to predict how likely an area was to vote Leave, what we really seek to understand is why groups with these particular demographic characteristics may have felt particularly compelled to vote Leave. Our approach is partly informed by our ongoing qualitative research into the Brexit result. We now begin to interpret the results by turning to the key role that social identity appears to have played in the result.

\section{Social Identity and Group Polarisation}

It is widely believed that immigration was a key factor driving the decision to leave the EU (M. Goodwin \& Milazzo, 2017). Research suggests that a perceived threat from immigrant "outgroups" was a predictive factor in voting to Leave (Van de Vyver, Leite, Abrams, \& Palmer, 2018). This perceived threat from immigration could have been accentuated by increases in immigration levels in areas with strong Leave votes (M. Goodwin \& Milazzo, 2017; M. J. Goodwin \& Heath, 2016).

Most evidence suggests that immigration has only modest (usually positive) effects on the wages of natives (Dustmann, Frattini, \& Preston, 2013; Ottaviano \& Peri, 2012) and European migration in particular has had a positive impact on the UK's fiscal position (Dustmann \& Frattini, 2014). As a result, concern over migration is difficult to explain from the perspective 
De Ruyter, A. \& Nielsen, B. (2018). Brexit: one year on from Article 50 - Reflections from Academia, Business and Politics

of pure economic self-interest ${ }^{5}$, so contemporary research has tended to focus on other factors (McLaren \& Johnson, 2007), implying that broader issues such as identity are likely to be at play here.

Social identity theory (SIT) was developed to account for how and why individuals from disadvantaged minority groups often do not directly confront dominant societal majority groups, even if their group is disadvantaged (Hogg \& Abrams, 1988; Tajfel, 1978). The theory may help explain why those who were less likely to identify as European are more likely to vote Leave (Van de Vyver et al., 2018). SIT, suggests that a portion of an individual's selfconcept is derived from their perceived or actual membership of certain social groups, as well as their non-membership to other groups. An influx of incomers can threaten self-identity, causing anxiety and negative contact encounters.

Class is a further marker of identity. Those who self-identify as working-class tend to have more authoritarian and less pro-immigrant opinions (NatCen Social Research, 2016). These are also views that are typically associated with pro-Brexit voting patterns. Class is a fascinating avenue to explore, because Brexit has ignited passions that are difficult to reconcile with an issue that is primarily technical in nature (those whose eyes glaze over at a discussion of models of trade have suddenly found that membership of a customs union is an issue of profound and totemic importance to them).

A person's social identity and perceived threat from out-groups can influence voting intentions and behaviours (Van de Vyver et al., 2018). Research suggests that identity (and particularly English identity) is a crucial motivating factor for voting Leave (Henderson et al., 2016). One's social identity is important to health and wellbeing (Jetten, Haslam, \& Haslam, 2012), but the perceived threat from those who do not share our social identity, or out-group members, can lead to some strong views. For example, one participant in our qualitative work on attitudes towards Brexit said, "The Islamic group is a clear and present danger to western civilization and it needs to be banned. It will never be assimilated or integrated and its stated aim is to overwhelm and out breed the indigenous peoples of Europe".

\footnotetext{
${ }^{5}$ Although there is something of a consensus in the literature, this view is by no means universally held ((e.g. Borjas, 2003). There is some evidence that immigration may have had a modestly deleterious effect on incomes in the bottom two deciles (Dustmann et al., 2013) but this struggles to explain why immigration was such a salient issue for a majority of voters - particularly those above retirement age.
} 
De Ruyter, A. \& Nielsen, B. (2018). Brexit: one year on from Article 50 - Reflections from Academia, Business and Politics

There certainly seems to be a sense of threat, "I am happy for immigrants to come to Britain. However, they should come with respect for the people who live here and respect our culture. They should not come and expect the country to become more like their native country, because we're our own country with our own culture and our own principles. Britain should stay British, but welcome immigrants to share our cultural values, otherwise what makes Britain a separate country from other places in the world?" (Semmens-Wheeler \& Hill, In prep.)

Fear about sharing economic and social resources has the potential to create group polarisation. Some evidence finds that unfavourable economic conditions are typically linked to stronger anti-immigrant sentiment (Meuleman, 2011;). The deep recession of 2008 and tepid recovery appears to have seen a hardening in attitudes towards immigration, particularly because threat leads to increased in-group identification at the cost of the outgroup (Castano, Yzerbyt, Paladino, \& Sacchi, 2002). Another psychological theory that could explain this phenomenon is Intergroup Threat Theory (ITT) (Stephan, Ybarra, \& Morrison, 2009).

ITT suggests that prejudice and negative attitudes towards out-groups (e.g. immigrants) can be explained by both realistic threats and symbolic threats. The former influence physical wellbeing and the economic and political power of the in-group. The latter come from cultural differences in values, morals, worldviews and negative stereotypes from the in-group about the out-group (Stephan et al., 2009). Additionally, intergroup anxiety is experienced by the in-group when interacting with out-group members. This theory could be used to explain how EU immigrants are seen as a potentially harmful out-group by non-EU-migrant in-groups, through the perceived competition for limited resources (i.e. realistic threat).

This, in turn, could lead to hostility towards the out-group, which may have been expressed in a vote to leave the EU. It is also possible that people voted for the EU against their own interests because of a perceived symbolic threat that the values of their in-group could be at risk. Other factors, such as socioeconomic status (SES) can be linked to threat perceptions. For example, those with lower SES are more reactive to threat (Kraus, Horberg, Goetz, \& Keltner, 2011). It is likely this was a contributory factor to the high proportion of Leave voters among lower SES groups (Skinner \& Gottfried, 2016), particularly given that research has alluded to a 'geography of discontent' (Los, McCann, Springford, \& Thissen, 2017). If certain 
De Ruyter, A. \& Nielsen, B. (2018). Brexit: one year on from Article 50 - Reflections from Academia, Business and Politics

areas are experiencing discontent due to perceived deprivation, slowing productivity and limited investment then this could be combined with fears related to immigration leading some to hypothesise that these left-behind areas drove the vote (Rodríguez-Pose, 2018). Given the strong incentives to relocate that a lack of local opportunity creates, it is unsurprising that individuals who remain in such areas feel that EU membership has not benefitted them.Low political trust amplifies existing anti-immigration sentiments (Abrams \& Travaglino, 2018). In this context, it is significant that trust in politicians in the UK is near alltime lows \& has fallen since the financial crisis \& recession (Freeguard, 2015). This is particularly true of trust in Brussels as the Brexit vote has demonstrated.

\section{Terror Management Theory}

For some, voting to leave the EU could have been an expression of fear and hostility. This is further explained by TMT. Terror Management Theory (TMT) (Greenberg, Pyszczynski, \& Solomon, 1986) highlights the motivational significance of our uniquely human awareness of mortality. According to Becker, in the absence of certain compelling psychological protective mechanisms, the knowledge that we are one day going to die creates the potential for severe dread. Greenberg et al. (1986) posit that when threat is activated, one's own cultural worldviews are even more strongly adhered to. For example, when people are afraid, people tend to cling even more strongly to their own cultural worldviews and are likely to stand by their values more. This, in turn, may strengthen in-group and out-group polarisation (Van de Vyver et al., 2018). Areas with high immigration benefitted from trade with the EU through industry, yet still voted Leave. This could involve Leave voters seeing the EU as an out-group, or anyone who does not appear to share their worldview, such as politicians, or immigrants.

It is important to note that the UK's low SES 'left-behind' are not the only socially distinct group to show a trend for voting in favour of Brexit. Declining economic conditions have led to the emergence of what has been referred to as "the squeezed middle", self-identified middle class individuals who perceive a decline in their socioeconomic circumstances and whose incomes have reduced, in real terms, by 8.7 percent (Milliard, 2014; Strauss, 2018). This group also contributed strongly to the Leave vote (Antonucci, Horvath, Kutiyski, \& 
De Ruyter, A. \& Nielsen, B. (2018). Brexit: one year on from Article 50 - Reflections from Academia, Business and Politics

Krouwel, 2017). Clearly, then, working classes are not the only social groups to feel left behind by globalisation and the widening economic gap.

Locus of Control

Research has shown that individuals with lower Socioeconomic status (SES) tend to have lower sense of control (Kraus, Piff, \& Keltner, 2009), feel politically excluded and experience having less control over socio-political issues. They also tend to focus on external uncontrollable forces that influence their lives. Those with an external locus of control tend to have more anti-immigrant attitudes, which are related to (but distinct from) racial prejudice (Harell, Srokora, \& Iyengar, 2017). This could, therefore contribute to blaming the EU, politicians, immigration, et cetera, for their life circumstances, and a chance to change the status quo by voting to leave the EU.

Populist movements have capitalised on the predicament of the left behind, arguing that the cosmopolitan elite disregard the lower, 'left-behind' classes, allowing low-skilled immigration to increase competition for jobs and failing to help communities to recover from the effects of recession (Lee et al., 2018). Understandably, then, the "left-behind" in Britain tend to feel that they have little power over events in their lives. Indeed, participants in our own research described feeling that the areas in which they lived received little to no investment from the government. One man in a small town in Lincolnshire said "All the money goes to London... all their transport links. We don't see any of the money." (De Ruyter et al., 2018, Forthcoming; Semmens-Wheeler \& Hill, In prep.)

External locus of control in low SES areas may combine with lack of 'openness', a psychological trait that encompasses curiosity and an openness to new and unconventional ideas (McCrae \& Costa, 2004). This trait is regionally clustered (Garretsen, Stoker, Soudis, Martin, \& Rentfrow, 2018) and, again, low levels of openness (characterised by preference for familiarity, routine and being relatively closed to new experiences) are seen in low SES area.. For example, higher areas of agreeableness and openness have been found to predict a Remain vote, whereas other traits, such as neuroticism and extraversion have been found to 
De Ruyter, A. \& Nielsen, B. (2018). Brexit: one year on from Article 50 - Reflections from Academia, Business and Politics

promote Leave votes. Particular regions also appear to have a higher anti-immigrant sentiment (Czaika \& Di Lillo, 2018). There appears to be significant spatial dependence proximate regions exhibit similar attitudes towards immigrants. Within the UK, London, the South East, Scotland and Northern Ireland all exhibit slightly lower anti-immigrant attitudes towards those of different ethnicity.

This does appear to coincide with regions where the vote in favour of Brexit was the least strong, raising the possibility of common factors. Certainly, London, the South East and Scotland all have educational attainment levels higher than other regions in Great Britain. Research suggests that graduates tend to have increased agreeableness, particularly if they are from disadvantaged backgrounds (Kassenboehmer, Leung, \& Schurer, 2018) and a higher level of education has been linked to a higher locus of control than in lower education (e.g. high school or less) (Smith, 2003). This is interesting given the links between Higher Education and voting preferences.

\section{Summary and Conclusions}

A number of factors appear to have had an impact on the Brexit vote. To a large extent our findings mirror earlier research, although there are nuances. Education appears to be a crucial factor, as does exposure to immigration. Even after controlling for other variables, areas with a large young population tended to have a higher "remain" vote, although the same does not appear to be true amongst the very old, reinforcing the findings of Liberini et al. (2017). LAs in Scotland had a much lower propensity to vote Leave than other areas. The West Midlands, on the other hand, voted Leave particularly strongly, even after accounting for demographic factors. Social class also appears to have played a strong role and, of course, migration proved to be every bit as critical as anecdotal evidence suggested.

A variety of social-psychological factors appear to have played a significant role in driving this, with social identity, group polarisation and intergroup threat theory all apparently driving some of the antipathy towards high levels of immigration. Similarly, groups experiencing a low locus of control appear to have voted Leave more strongly with low political trust 
De Ruyter, A. \& Nielsen, B. (2018). Brexit: one year on from Article 50 - Reflections from Academia, Business and Politics

amplifying these trends. The upshot is that work on understanding both the socio-economic environment and psychological processes underlying the populist votes of the early $21^{\text {st }}$ century, of which Brexit is just one, is still in its infancy and future cross-disciplinary collaboration is essential if we are to develop a holistic understanding of them.

\section{References:}

Abrams, D., \& Travaglino, G. A. (2018). Immigration, political trust, and Brexit - Testing an aversion amplification hypothesis. Br J Soc Psychol, 57(2), 310-326. doi:10.1111/bjso.12233

Antonucci, L., Horvath, L., Kutiyski, Y., \& Krouwel, A. (2017). The malaise of the squeezed middle: Challenging the narrative of the 'left behind' Brexiter. Competition \& Change, 21(3), 211-229. doi:10.1177/1024529417704135

Ashcroft, M. (2016). How the United Kingdom voted on Thursday... and why. Retrieved from https://lordashcroftpolls.com/2016/06/how-the-united-kingdom-voted-and-why/

Becker, S. O., Fetzer, T., \& Novy, D. (2017). Who voted for Brexit? A comprehensive district-level analysis. Economic Policy, 32(92), 601-650. doi:10.1093/epolic/eix012

Borjas, G. J. (2003). The Labor Demand Curve is Downward Sloping: Reexamining the Impact of Immigration on the Labor Market*. The Quarterly Journal of Economics, 118(4), 1335-1374. doi:10.1162/003355303322552810

Castano, E., Yzerbyt, V., Paladino, M.-P., \& Sacchi, S. (2002). I Belong, therefore, I Exist: Ingroup Identification, Ingroup Entitativity, and Ingroup Bias. Personality and Social Psychology Bulletin, 28(2), 135-143. doi:10.1177/0146167202282001

Czaika, M., \& Di Lillo, A. (2018). The geography of anti-immigrant attitudes across Europe, 2002-2014. Journal of Ethnic and Migration Studies, 1-27. doi:10.1080/1369183X.2018.1427564

De Ruyter, A., Hearne, D., Guy, J., Semmens-Wheeler, R., \& Goodwin, B. (2018, Forthcoming). Tales from an Episodic Journey into "Brexitland": Understanding the Underlying Factors as to Why People Voted "Leave". CBS Working Paper.

Dustmann, C., \& Frattini, T. (2014). The Fiscal Effects of Immigration to the UK. The Economic Journal, 124(580), F593-F643. doi:doi:10.1111/ecoj.12181

Dustmann, C., Frattini, T., \& Preston, I. P. (2013). The Effect of Immigration along the Distribution of Wages. The Review of Economic Studies, 80(1), 145-173. doi:10.1093/restud/rds019

Electoral Commission. (2016). EU referendum results. Retrieved from https://www.electoralcommission.org.uk/find-information-by-subject/elections-andreferendums/past-elections-and-referendums/eu-referendum/electorate-and-countinformation

Fielding, D. (2018). 1066 and all that: Some deep determinants of voting shares in the 2016 referendum on EU membership. The World Economy, 41(4), 1131-1146. doi:doi:10.1111/twec.12621

Financial Times (Producer). (2013). FT Austerity Audit. Retrieved from https://ig.ft.com/austeritymap/

Freeguard, G. (2015, 5th February 2015). Public trust in public servants - in six graphs. Retrieved from https://www.instituteforgovernment.org.uk/blog/public-trust-public-servants-\%E2\%80\%93six-graphs

Garretsen, H., Stoker, J. I., Soudis, D., Martin, R. L., \& Rentfrow, P. J. (2018). Brexit and the relevance of regional personality traits: more psychological Openness could have swung the regional vote. Cambridge Journal of Regions, Economy and Society, 11(1), 165-175. doi:10.1093/cjres/rsx031 
De Ruyter, A. \& Nielsen, B. (2018). Brexit: one year on from Article 50 - Reflections from Academia,

Business and Politics

Goodwin, M., \& Milazzo, C. (2017). Taking back control? Investigating the role of immigration in the 2016 vote for Brexit. The British Journal of Politics and International Relations, 19(3), 450-464. doi:10.1177/1369148117710799

Goodwin, M. J., \& Heath, O. (2016). The 2016 Referendum, Brexit and the Left Behind: An Aggregatelevel Analysis of the Result. The Political Quarterly, 87(3), 323-332. doi:10.1111/1467923X.12285

Greenberg, J., Pyszczynski, T., \& Solomon, S. (1986). The Causes and Consequences of a Need for SelfEsteem: A Terror Management Theory. In R. F. Baumeister (Ed.), Public Self and Private Self. New York: Springer-Verlag.

Harell, A., Srokora, S., \& lyengar, S. (2017). Locus of Control and Anti-Immigrant Sentiment in Canada, the United States, and the United Kingdom. Political Psychology, 38(2), 345-360.

Henderson, A., Jeffery, C., Liñeira, R., Scully, R., Wincott, D., \& Wyn Jones, R. (2016). England, Englishness and Brexit. The Political Quarterly, 87(2), 187-199. doi:10.1111/1467-923X.12262

Hogg, M. A., \& Abrams, D. (1988). Social identifications : a social psychology of intergroup relations and group processes. London: Routledge.

Jetten, J., Haslam, C., \& Haslam, S. A. (2012). The social cure : identity, health and well-being. Hove: Psychology Press.

Kassenboehmer, S. C., Leung, F., \& Schurer, S. (2018). University education and non-cognitive skill development. Oxford Economic Papers, 70(2), 538-562. doi:10.1093/oep/gpy002

Kraus, M. W., Horberg, E. J., Goetz, J. L., \& Keltner, D. (2011). Social class rank, threat vigilance, and hostile reactivity. Pers Soc Psychol Bull, 37(10), 1376-1388. doi:10.1177/0146167211410987

Kraus, M. W., Piff, P. K., \& Keltner, D. (2009). Social class, sense of control, and social explanation. J Pers Soc Psychol, 97(6), 992-1004. doi:10.1037/a0016357

Lee, N., Morris, K., \& Kemeny, T. (2018). Immobility and the Brexit vote. Cambridge Journal of Regions, Economy and Society, 11(1), 143-163. doi:10.1093/cjres/rsx027

Liberini, F., Oswald, A., Proto, E., \& Redoano, M. (2017). Was Brexit caused by the unhappy and the old? CAGE Working Paper 342, Warwick University.

Los, B., McCann, P., Springford, J., \& Thissen, M. (2017). The mismatch between local voting and the local economic consequences of Brexit. Regional Studies, 51(5), 786-799. doi:10.1080/00343404.2017.1287350

McCrae, R. R., \& Costa, P. T. (2004). A contemplated revision of the NEO Five-Factor Inventory. Personality and Individual Differences, 36(3), 587-596. doi:https://doi.org/10.1016/S01918869(03)00118-1

McLaren, L., \& Johnson, M. (2007). Resources, Group Conflict and Symbols: Explaining AntiImmigration Hostility in Britain. Political Studies, 55(4), 709-732. doi:doi:10.1111/j.14679248.2007.00680.x

Meuleman, B. (2011). Perceived Economic Threat and Anti-Immigration Attitudes: Effects of Immigrant Group Size and Economic Conditions Revisited. In E. Davidov, P. Schmidt, \& J. Billiet (Eds.), Cross Cultural Analysis: Methods and Applications. New York: Routledge.

Milliard, R. (2014). Are you stuck in the Squeezed Middle? Why we're feeling the pinch like never before. Daily Mail. Retrieved from https://www.dailymail.co.uk/home/you/article2575538/Are-stuck-Squeezed-Middle-Why-feeling-pinch-like-never-before.html

NatCen Social Research. (2016). British Social Attitudes. 33. Retrieved from http://www.bsa.natcen.ac.uk/latest-report/british-social-attitudes-33/introduction.aspx

Office for National Statistics. (2017a). Annual Population Survey Jan-Dec 2016. Retrieved 22nd August 2018, from ONS https://www.nomisweb.co.uk/query/construct/summary.asp?mode=construct\&version=0\& dataset $=17$

Office for National Statistics. (2017b). Annual Survey of Hours and Earnings, 1997-2016

Office for National Statistics. (2017c). Regional gross value added (balanced), UK: 1998 to 2016. from Office 
De Ruyter, A. \& Nielsen, B. (2018). Brexit: one year on from Article 50 - Reflections from Academia, Business and Politics

https://www.ons.gov.uk/economy/grossvalueaddedgva/bulletins/regionalgrossvalueaddedb alanceduk/1998to2016

Ottaviano, G. I. P., \& Peri, G. (2012). RETHINKING THE EFFECT OF IMMIGRATION ON WAGES. Journal of the European Economic Association, 10(1), 152-197. doi:doi:10.1111/j.15424774.2011.01052.x

Rodríguez-Pose, A. (2018). Commentary: The revenge of the places that don't matter (and what to do about it). Cambridge Journal of Regions, Economy and Society, rsx024-rsx024. doi:10.1093/cjres/rsx024

Semmens-Wheeler, R., \& Hill, K. (In prep.). Understanding the perceptions of voters in rural and regional England on Brexit.

Semyonov, M., Raijman, R., \& Gorodzeisky, A. (2006). The Rise of Anti-foreigner Sentiment in European Societies, 1988-2000. American Sociological Review, 71(3), 426-449. doi:10.1177/000312240607100304

Skinner, G., \& Gottfried, G. (2016). How Britain voted in the 2016 EU referendum. Retrieved from https://www.ipsos.com/ipsos-mori/en-uk/how-britain-voted-2016-eu-referendum

Smith, V. L. (2003). ANALYSIS OF LOCUS OF CONTROL AND EDUCATIONAL LEVEL UTILIZING THE INTERNAL CONTROL INDEX. Theses, Dissertations and Capstones, Paper 881.

Stephan, W. G., Ybarra, O., \& Morrison, K. R. (2009). Intergroup Threat Theory. In T. D. Nelson (Ed.), Handbook of Prejudice, Stereotyping, and Discrimination. Hove: Taylor \& Francis.

Strauss, D. (2018). Squeezed middle faces growing risk of poverty: OECD research shows widening divide between the lower and upper middle classes. Financial Times. Retrieved from https://www.ft.com/content/13fe209e-707f-11e8-852d-d8b934ff5ffa

Tajfel, H. (1978). Differentiation between social groups : studies in the social psychology of intergroup relations. London: Academic Press [for] European Association of Experimental Social Psychology.

Van de Vyver, J., Leite, A. C., Abrams, D., \& Palmer, S. B. (2018). Brexit or Bremain? A person and social analysis of voting decisions in the EU referendum. Journal of Community \& Applied Social Psychology, 28(2), 65-79. doi:doi:10.1002/casp.2341 